\title{
Precipitation effects of giant cloud condensation nuclei artificially introduced into stratocumulus clouds
}

\author{
E. Jung ${ }^{1}$, B. A. Albrecht ${ }^{1}$, H. H. Jonsson ${ }^{2}$, Y.-C. Chen ${ }^{3,4}$, J. H. Seinfeld ${ }^{3}$, A. Sorooshian ${ }^{5}$, A. R. Metcalf ${ }^{3,}{ }^{*}$, S. Song ${ }^{1}$, \\ M. Fang ${ }^{1}$, and L. M. Russell ${ }^{6}$ \\ ${ }^{1}$ Rosenstiel School of Marine and Atmospheric Science, University of Miami, Miami, FL, USA \\ ${ }^{2}$ Center for Interdisciplinary Remotely-Piloted Aircraft Studies, Naval Postgraduate School, Monterey, California, USA \\ ${ }^{3}$ California Institute of Technology, Pasadena, California, USA \\ ${ }^{4}$ Jet Propulsion Laboratory, California Institute of Technology, Pasadena, California, USA \\ ${ }^{5}$ Department of Chemical and Environmental Engineering, and Department of Atmospheric Sciences, \\ University of Arizona, Tucson, Arizona, USA \\ ${ }^{6}$ Scripps Institution of Oceanography, University of California, San Diego, La Jolla, California, USA \\ *now at: Department of Mechanical Engineering, University of Minnesota, Minneapolis, Minnesota, California, USA
}

Correspondence to: E. Jung (eunsil.jung@ gmail.com)

Received: 7 November 2014 - Published in Atmos. Chem. Phys. Discuss.: 7 January 2015

Revised: 6 April 2015 - Accepted: 11 April 2015 - Published: 22 May 2015

\begin{abstract}
To study the effect of giant cloud condensation nuclei (GCCN) on precipitation processes in stratocumulus clouds, $1-10 \mu \mathrm{m}$ diameter salt particles (salt powder) were released from an aircraft while flying near the cloud top on 3 August 2011 off the central coast of California. The seeded area was subsequently sampled from the aircraft that was equipped with aerosol, cloud, and precipitation probes and an upward-facing cloud radar. During post-seeding sampling, made 30-60 min after seeding, the mean cloud droplet size increased, the droplet number concentration decreased, and large drop (e.g., diameter larger than $10 \mu \mathrm{m}$ ) concentration increased. Average drizzle rates increased from about 0.05 to $0.20 \mathrm{~mm} \mathrm{~h}^{-1}$, and the liquid water path decreased from about 52 to $43 \mathrm{~g} \mathrm{~m}^{-2}$. Strong radar returns associated with drizzle were observed on the post-seeding cloud-base levelleg flights and were accompanied by a substantial depletion of the cloud liquid water content. The changes were large enough to suggest that the salt particles with concentrations estimated to be $10^{-2}$ to $10^{-4} \mathrm{~cm}^{-3}$ resulted in a four-fold increase in the cloud-base rainfall rate and depletion of the cloud water due to rainout. In contrast, a case is shown where the cloud was already precipitating (on 10 August) and the effect of adding GCCN to the cloud was insignificant.
\end{abstract}

\section{Introduction}

The stratocumulus $(\mathrm{Sc})$ cloud deck is the most persistent cloud type in the world, and the variations of the cloud amount and the albedo can significantly impact the climate system through their radiative effects on the earth system (e.g., Hartmann et al., 1992; Slingo, 1990). The addition of small amounts of giant cloud condensation nuclei (GCCN) to stratocumulus cloud may have little direct impact on radiative effects, but the impacts may be significant if the GCCN can initiate or enhance precipitation (Jensen and Lee, 2008). Nonetheless, the role of GCCN in precipitation production in stratocumulus clouds is less explored compared with the substantial work that has been done on other types of clouds (e.g., Takahashi, 1976; Johnson, 1982; Tzivion et al., 1994; Mather et al., 1997; Yin et al., 2000a, b; World Meteorological Organization, 2000; Levin et al., 2005; Rosenfeld et al., 2010). Therefore, our study focuses on the role of GCCN in stratocumulus clouds.

The role of GCCN in precipitation production in stratocumulus clouds has been explored using large eddy simulation (LES) and parcel models (Feingold et al., 1999; Lu and Seinfeld, 2005; Jensen and Lee, 2008). These studies show that GCCN introduced into non-precipitating stratocumulus clouds can promote the growth of drizzle drops by enhancing collision and coalescence processes. Analysis of NASA A- 
Train data also suggests that enhanced levels of sea salt particles over the ocean lead to faster collision-coalescence and accelerated precipitation responses (L'Ecuyer et al., 2009; Sorooshian et al., 2013). Despite this basic understanding, observing the effects of GCCN in real clouds with in situ measurements is challenging. First, GCCN concentrations in nature (order $10^{-4}$ to $10^{-2} \mathrm{~cm}^{-3}$ ) are many orders of magnitude less than $\mathrm{CCN}$ concentrations (order $10^{2} \mathrm{~cm}^{-3}$ ), and thus are difficult to measure. Second, cause-and-effect relationships involving GCCN are difficult to isolate under natural conditions, since other factors can affect and modulate drizzle production.

Marine stratocumulus clouds present laboratory-like conditions for evaluating how GCCN modify cloud properties. By introducing GCCN directly into a uniform cloud, the role that other factors may have in modifying the cloud can be minimized, and the background cloud conditions can be compared with the seeded cloud areas as shown by Ghate et al. (2007). The seeding by Ghate et al. (2007) used flares (in the size range of $0.1-2 \mu \mathrm{m}$ ) to produce hygroscopic particles in clouds ranging in size between 1 and $5 \mu \mathrm{m}$. The seeded cloud was then sampled with an instrumented aircraft flying within the Sc to examine the effects of the seeding on the cloud.

Flares, however, generate high number concentrations of small CCN particles simultaneous with far fewer giant CCN, and may not be optimal as seeder particles. Tzivion et al. (1994), Cooper et al. (1997), and Yin et al. (2000b), for example, showed that positive cloud responses to seeding (i.e., shift of size distribution toward larger sizes; enhanced precipitation) increase with the size of the seeding particles. In particular, the particles (diameter) smaller than $2 \mu \mathrm{m}$ had a negative effect on the rain development in convective clouds (Yin et al., 2000b) based on the flares used in the South Africa seeding experiment (Mather et al., 1997). Furthermore, Segal et al. (2004), based on a 2000-bin spectral cloud parcel model, predicted that hygroscopic-seeding materials with diameters of 3-6 $\mu \mathrm{m}$ are optimal for enhancing precipitation in warm clouds. They also predicted that smaller-sized CCN aerosols suppress precipitation as shown in Yin et al. (2000b) and L'Ecuyer et al. (2009). L'Ecuyer et al. (2009) showed that the injection of sea salt and sulfate aerosols into warm maritime clouds leads to nearly opposite cloud responses. The addition of large-sized sea salt particles was found to enhance precipitation and lead to less vertically developed clouds, whereas addition of the considerably smaller-sized sulfate particles suppresses precipitation in clouds and results in the onset of light precipitation in clouds with higher liquid water paths.

The purpose of this paper is to report on results from airborne flights examining the role that GCCN play in initiating precipitation in Sc clouds. To introduce GCCN without increasing the number of small-sized CCN that can suppress precipitation (e.g., Segal et al., 2007; L'Ecuyer et al., 2009), we employed a technique developed by Rosenfeld et al. (2010) who injected milled salt particles into convective cumuli. In the case we present here, GCCN in the form of milled salt particles were dispersed into uniform Sc clouds from an aircraft flying near the cloud top. After the GCCN were introduced into the cloud, the aircraft sampled the seeded cloud deck with in situ instruments and an upward-facing cloud radar.

\section{Instruments and techniques}

\subsection{Aircraft data}

The data used in this study were obtained from the Center for Interdisciplinary Remotely Piloted Aircraft Studies (CIRPAS) Twin Otter (TO) aircraft that was flown in support of the Eastern Pacific Emitted Aerosol Cloud Experiment (EPEACE, 2011), which took place off the central coast of California during July and August 2011 (Russell et al., 2013). The CIRPAS TO research aircraft was instrumented with (1) three in situ probes that characterize aerosol, clouds, and precipitation size distributions, (2) standard meteorological instruments that measure the atmospheric thermodynamic and wind structures, and (3) an upward-facing frequency modulated continuous wave (FMCW) cloud radar. Three probes relevant to this study were (1) the Passive Cavity Aerosol Spectrometer Probe (PCASP), (2) the Cloud Aerosol Spectrometer (CAS), and (3) the Cloud Imaging Probe (CIP), which resolve particles in diameter ranges from 0.1 to 3 , 0.6 to 60 and 25 to $1550 \mu \mathrm{m}$, respectively. The FMCW cloud radar (operating at a wavelength of $3 \mathrm{~mm}$ ) was mounted on top of the aircraft, and provided fine structures of cloud and precipitation (vertical resolution of $5 \mathrm{~m}$ and temporal resolution of $3 \mathrm{~Hz}$ ). The aerosol, cloud and precipitation probe data were obtained at $1 \mathrm{~Hz}$ resolution, and the meteorological variables (e.g., temperature, humidity, winds, Gerber probe liquid water content, etc.) were acquired at both 1 and $10 \mathrm{~Hz}$ resolutions. For detailed information on the probes and the cloud radar used in this study, see Russell et al. (2013), and Table 1 and Fig. 1 of Jung and Albrecht (2014).

\subsection{Salt powder and salt distribution system}

The salt powder comprises milled salt particles coated with an agent to minimize sticking as described by Rosenfeld et al. (2010). We measured the size distribution of the salt in the laboratory by delivering powder to the viewing volume of the CAS using an atomizer bottle. The number and volume (percent) size distribution are shown in Fig. 1. The number concentrations are relatively constant in the diameter range of 0.8 to $12 \mu \mathrm{m}$, with a peak in the volume distribution at 10 $12 \mu \mathrm{m}$. There are relatively few particles smaller than $0.8 \mu \mathrm{m}$ or larger than $12 \mu \mathrm{m}$. The effective volume diameter (i.e., the diameter that would give the average volume of the distribution) is about $5 \mu \mathrm{m}$. 

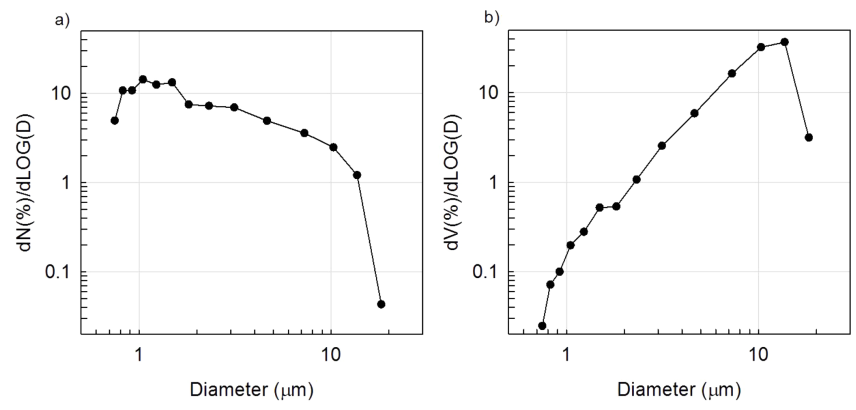

Figure 1. Relative (percent of total) (a) number and (b) volume distributions of powdered salt delivered to the CAS sampling volume from the atomizer.

To eject these particles from the aircraft into the clouds, we designed and fabricated a fluidized bed delivery system. The apparatus used an auger to feed salt powder at a controllable rate from a reservoir into a fluidized bed of sandblasting grit from which a filtered pump exhaust ejected the salt powder into the airstream outside the aircraft. The flow into the fluidized bed was baffled to give a uniform airflow through a fine mesh membrane at the base of the bed, and the flow was adjusted such that the salt powder, but not the grit, was ejected. The purpose of delivering the powder through this fluidized bed was to break up salt particles that might be stuck together. Laboratory tests were carried out to determine auger delivery rates, and to determine proper flow rates to eject salt only while preserving the grit throughout the delivery. The salt delivery system was set to disperse the salt powder at a rate of about $0.75 \mathrm{~g} \mathrm{~s}^{-1}$, which was intended to give GCCN concentrations of an order $10^{-2}$ to $10^{-4} \mathrm{~cm}^{-3}$. For an average salt particle diameter of $5 \mu \mathrm{m}$, we estimate that about $5 \times 10^{9}$ salt particles were emitted per second. A schematic and a photo of the salt powder delivery system are shown in Fig. 2.

Once the salt powder is emitted from the aircraft, it is dispersed, but the exact dispersal rate is unknown. The TO aircraft, with wing span of about $20 \mathrm{~m}$, flew at a speed of about $60 \mathrm{~m} \mathrm{~s}^{-1}$ during the salt dispersal. Assuming that initial dispersion due to aircraft induced turbulence extends more than twice its wingspan, the salt plume cross-sectional area may be expected to quickly expand to about $50 \times 50 \mathrm{~m}$. If $5 \times 10^{9}$ particles are emitted along the $60 \mathrm{~m}$ path flown in $1 \mathrm{~s}$, after $10 \mathrm{~min}$, the salt concentration would then be about $3.5 \times 10^{-2} \mathrm{~cm}^{-3}$. If the cross-sectional area of the plume expands to $100 \times 100 \mathrm{~m}$, the concentration would be reduced to about $1.7 \times 10^{-2} \mathrm{~cm}^{-3}$, and to about $1 \times 10^{-3} \mathrm{~cm}^{-3}$ for a $200 \times 200 \mathrm{~m}$ area. Thus, we estimate that after $10 \mathrm{~min}$ or more, the particle concentrations would be on the order of $10^{-2}$ to $10^{-3} \mathrm{~cm}^{-3}$, which lies in the range used in simulations by Feingold et al. (1999).

\section{Results}

\subsection{Seeding case}

During E-PEACE, salt powder was ejected into cloud decks during nine flights. However, due to the ineffective seeding and sampling strategies on some flights and the presence of precipitation at the time of seeding on others, we are able to identify only one case on 3 August 2011 in which seeding impacts are evident throughout the entire cloud deck depth. But, there are several cases showing seeding impacts exclusively at the cloud heights that are not precipitating at the time of seeding. It should be noted that the primary purpose of most of the flight plans (E-PEACE) was not the salt-seeding experiments. The summary of all the salt seeding experiments and flight patterns are shown in Fig. A1 and Table A1 in Appendix A to better understand the individual seeding cases.

In this study, we focus on the 3 August 2011 case, when a Sc cloud deck was sampled with the TO in an area $\left(35.8 .1-36.4 .1^{\circ} \mathrm{N} ; 122.8-122.2^{\circ} \mathrm{W}\right)$ about $100 \mathrm{~km}$ southwest of Monterey between 16:00 and 20:00 UTC. The boundary layer thermodynamic and aerosol vertical profiles, shown in Fig. 3, were obtained during a descent and an ascent of the aircraft through the cloud deck, approximately 10 30 min prior to flying horizontal background cloud-sampling legs, and about an hour prior to the cloud seeding. The cloud deck was about 300-350 m thick (Fig. 3b) and capped by an inversion (with inversion strength $\Delta \theta$ of $\sim 5-6 \mathrm{~K}$ ) at heights of about $625-645 \mathrm{~m}$ (Fig. 3a). The inversion strength calculated from these two profiles is slightly weaker than those calculated from the entire period of the experiments $(\Delta \theta$ $\sim 7 \pm 2 \mathrm{~K}$ based on 25 flights). By comparison, these are weaker than those reported at the coast of northern Chile in the southeastern Pacific during VOCALS-REx (e.g., $\sim 12 \mathrm{~K}$ from Zheng et al., 2011). The cloud liquid water content (LWC) profiles, Fig. 3b, are very consistent with those typical of a uniform, non-precipitating Sc cloud deck. The accumulation mode aerosol varies in concentration from 200 to $500 \mathrm{~cm}^{-3}$ in the sub-cloud layer in the ascent profile, and from 200 to $800 \mathrm{~cm}^{-3}$ above the cloud layer in both the ascent and descent soundings (Fig. 3c).

To estimate the natural number of GCCN, aerosol concentrations larger than $D>2 \mu \mathrm{m}, D>10 \mu \mathrm{m}, D>20 \mu \mathrm{m}$ were obtained from CAS on non-cloudy level flight legs flown near the ocean surface $(20-30 \mathrm{~m} ; 12$ min of duration) and above the cloud layer $(750 \mathrm{~m} ; 3 \mathrm{~min}$ of duration) as summarized in Table 1. These estimates indicate that the natural number of GCCN (e.g., $D>10 \mu \mathrm{m})$ above the cloud layer $(\sim 750 \mathrm{~m})$ was on the order of $10^{-3} \mathrm{~cm}^{-3}$ and, no GCCN larger than $20 \mu \mathrm{m}$ was observed there. On the other hand, the natural number of aerosols of GCCN with $D>10 \mu \mathrm{m}$ near the ocean surface (about $20-30 \mathrm{~m}$ above the sea level) was on the order of $10^{-2} \mathrm{~cm}^{-3}$, which was an order of magnitude larger than those above the cloud layer. Table 1 also showed that 

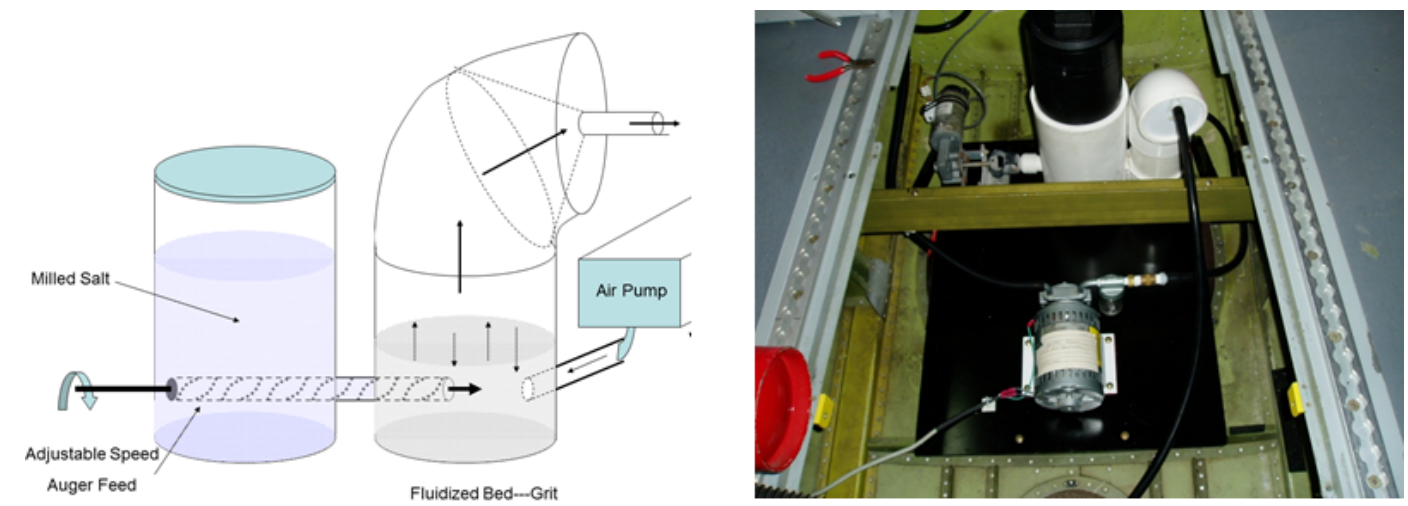

Figure 2. A pictorial schematic and photo of the salt-powder delivery system.

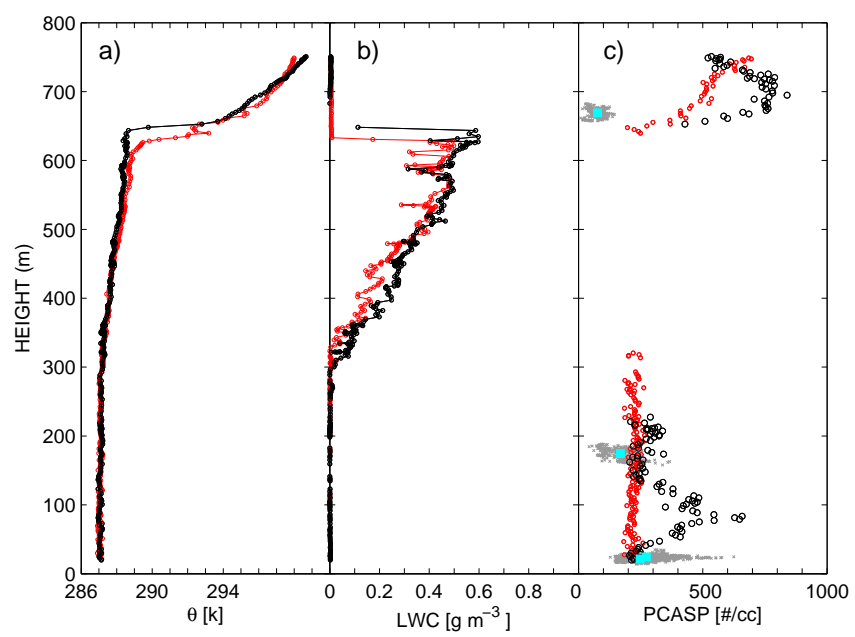

Figure 3. Profiles of (a) potential temperature $(\theta, \mathrm{K})$, (b) liquid water contents (LWC, $\mathrm{g} \mathrm{m}^{-3}$ ), and (c) accumulation mode aerosol concentrations (\#/cc, PCASP) during the aircraft ascent (black) and descent (red) between 16:52:15 and 17:10:48 UTC (hh:mm:ss). Aerosol concentrations obtained from sub-cloud layer and above cloud layer are shown as grey colors (mean value is shown as cyan square). The heights and spatial locations of data used are shown in Fig. 4. PCASP resolves particles in diameter ranges from 0.1 to $3 \mu \mathrm{m}$.

the GCCN concentrations in nature were on the same order as the GCCN concentrations that were estimated for the salt dispersed artificially. However, since no measurements of GCCN were made immediately below cloud base, we do not know the natural GCCN concentrations that were incorporated into the cloud.

On this particular day, the mean wind near the ocean surface was about $10 \mathrm{~m} \mathrm{~s}^{-1}$ and, thus, the higher concentration of GCCN near the ocean surface compared with those above the cloud layer was possibly contributed by the wave breaking. However, wind speeds near the ocean surface were nearly constant $\left(9.5 \pm 0.8 \mathrm{~m} \mathrm{~s}^{-1}\right)$ during the flight. Furthermore, since sea surface temperature (SST) remained
Table 1. GCCN concentrations obtained from CAS on 3 August 2011.

\begin{tabular}{lll}
\hline & $\begin{array}{l}\text { Near the ocean surface } \\
(\text { leg b in Fig. 4a) }\end{array}$ & $\begin{array}{l}\text { above the cloud layer } \\
(\text { around } 750 \mathrm{~m}, \sim 17: 00 \mathrm{UTC})\end{array}$ \\
\hline $\begin{array}{l}\text { Diameter } \\
(\mu \mathrm{m})\end{array}$ & $\begin{array}{l}\text { Concentrations } \\
\left(\mathrm{cm}^{-3}\right)\end{array}$ & $\begin{array}{l}\text { Concentrations } \\
\left(\mathrm{cm}^{-3}\right)\end{array}$ \\
\hline$D>2$ & 1.89 & $5 \times 10^{-2}$ \\
$D>10$ & $5.4 \times 10^{-2}$ & $3 \times 10^{-3}$ \\
$D>20$ & $9.5 \times 10^{-3}$ & -
\end{tabular}

nearly constant during the flight (ranging from $15.2 \pm 0.09$ to $15.5 \pm 0.1^{\circ} \mathrm{C}$ ), no major changes in the surface buoyancy and moisture fluxes were experienced. Therefore, there were no major changes in the background wind and the SST conditions that could cause variability of GCCN during the sampling legs of this flight.

\subsection{Sampling strategy}

Flight paths and time series of the altitudes flown on $3 \mathrm{Au}$ gust 2011 are shown in Fig. 4. Detailed information of each leg segment is summarized in Table 2. To characterize the background conditions, the clouds and the aerosol beneath them were sampled with in situ probes and the cloud radar at four altitude levels, including one sub-cloud layer and three cloud levels before the seeding (Fig. 4b-e), hereafter referred to as pre-seeding (cloud sampling) legs. The seeding flight pattern is shown in Fig. 4f. After seeding, the seeded cloud was sampled downwind of the seeded area at similar levels as characterized before (hereafter referred to as post-seeding (cloud sampling) legs). To ensure that the seeded areas were sampled, the post-seeding sampling areas (red in Fig. $4 \mathrm{~g}-\mathrm{i}$ ) were selected by using wind speed and wind direction measurements along the seeding path to advect the seed plume downstream.

The salt powder was dispersed as the TO flew near the cloud top (shown as thick blue in Fig. $4 \mathrm{f}-\mathrm{j}$ ). Note that this seeding flight pattern is almost identical to the pre-seeding 


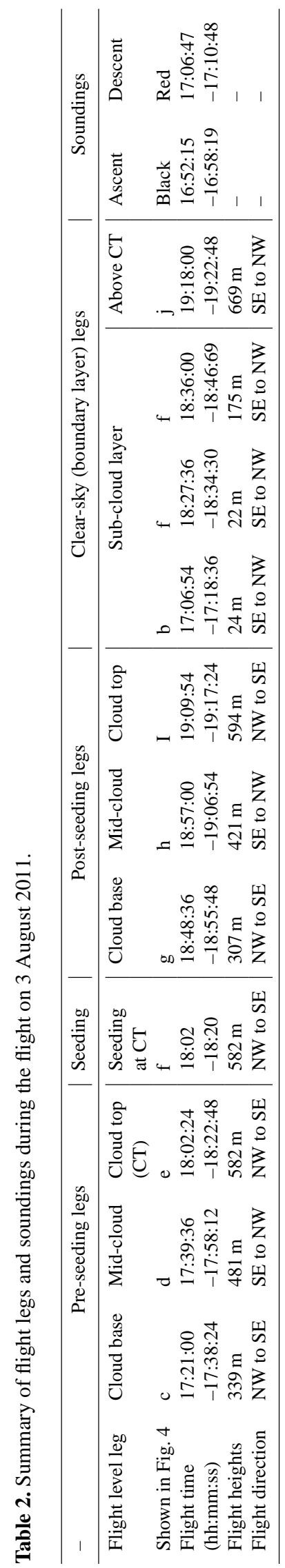



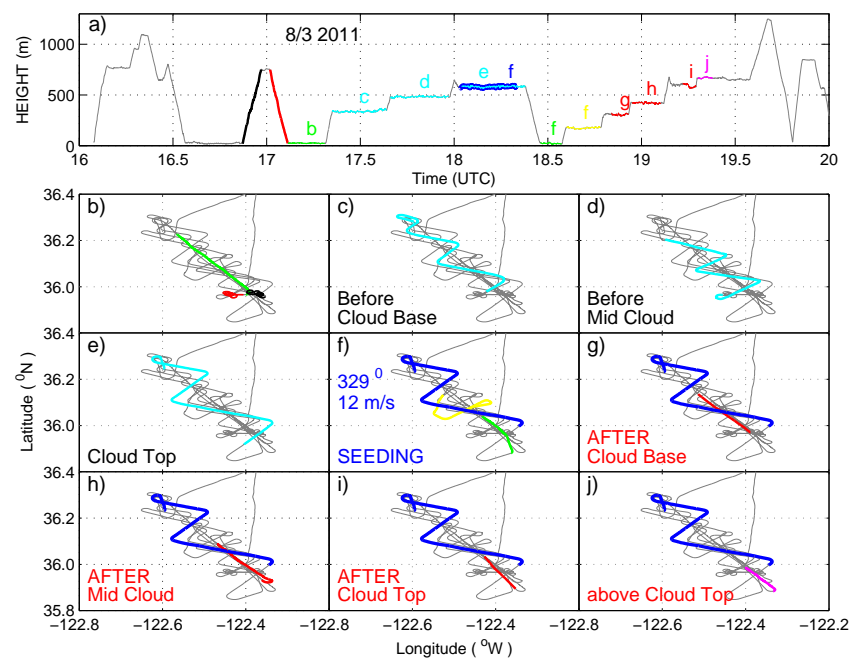

Figure 4. (a) Time series of flight altitudes and (b-j) flight paths on 3 August 2011. The flight pattern for salt seeding is shown as thick blue colors in $(\mathbf{f}-\mathbf{j})$. The mean wind speed $\left(12 \mathrm{~m} \mathrm{~s}^{-1}\right)$ and direction $\left(329^{\circ}\right)$ for the seeding period are shown in (f). Individual legs with corresponding colors are shown in each box accordingly. The detailed information of each level leg, such as flight heights and duration, is summarized in Table 2 .

cloud-top leg (Fig. 4e). During the seeding, the wind was $12 \mathrm{~m} \mathrm{~s}^{-1}$ from the northwest $\left(\sim 330^{\circ}\right)$. After seeding, the seeded air mass was sampled along the wind near cloud base (Fig. 4g), mid-cloud (Fig. 4h), and near cloud top (Fig. 4i). These post-seeding legs were made about 30-60 min after the clouds were seeded (Fig. 4a and Table 2).

The estimated post-seeding areas at cloud top, mid-cloud and cloud base are shown in Fig. 5 (grey shades), along with the seeding and post-seeding leg patterns. Here, the seeding pattern has been advected using the winds and elapsed time between seeding and post-seeding cloud sampling periods. If the cloud is seeded between $A$ (starting time of seeding legs) and $A^{\prime}$ (ending-time of seeding legs), and the post-seeding legs are made between $B$ (starting-time of post-seeding legs) and $B^{\prime}$ (ending-time of post-seeding legs), then four elapsed time periods are possible; (1) $A^{\prime}-B$, (2) $A^{\prime}-B^{\prime}$, (3) $A-B$, and (4) $A-B^{\prime}$. Here, $A^{\prime}-B\left(A-B^{\prime}\right)$ corresponds to the shortest (longest) elapsed time periods between the time of seeding and post-seeding and shown as the darkest (lightest) colors in Fig. 5. The post-seeding sampling-pattern (red) is located well within the advected (shaded) areas, showing that the seeded area is properly sampled during the post-seeding cloud sampling leg. To compare changes in cloud and precipitation properties between pre- and post-seeding legs, postseeding data from cloud sampling legs (red) made within the advected seeding area (i.e., grey shades) are used.

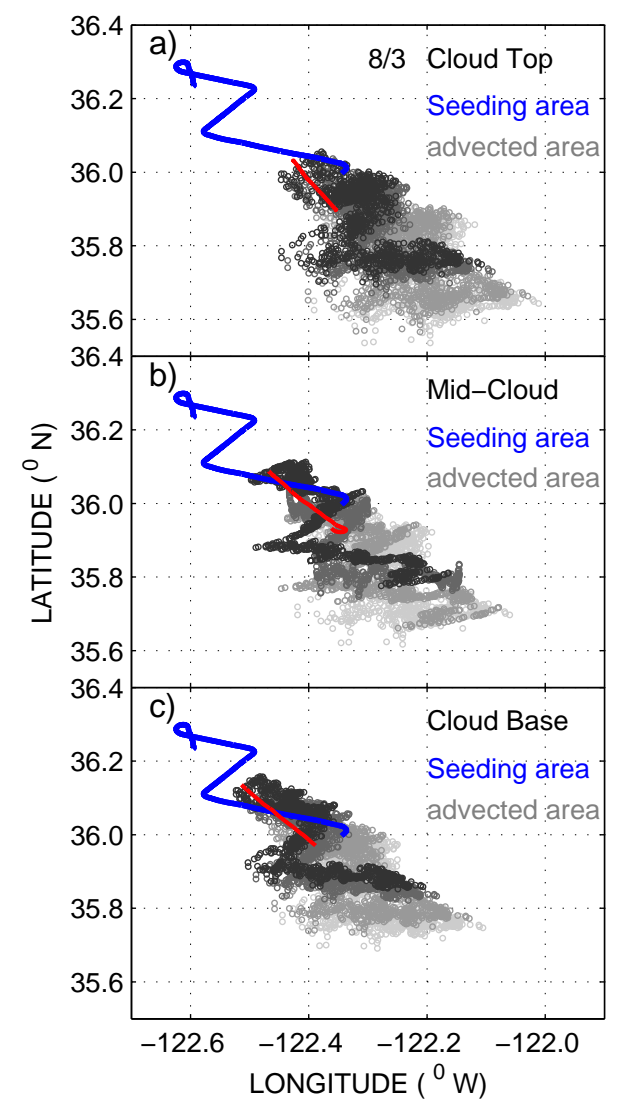

Figure 5. Salt seeding pattern (blue) with estimated advected seeding area at (a) cloud top, (b) mid-cloud and (c) cloud base. The seeding and post-seeding cloud sampling areas are shown as blue and red colors, respectively, at each level. The estimated seeding areas for the post-seeding flights are shown as grey shades. The darker grey area points are the advected points calculated with the shorter possible elapsed times.

\subsection{Seeding results}

Droplet size (effective diameter, $D$ ), number concentrations $\left(N_{d}\right)$, and precipitation rate $(R)$ measured on the pre- and post-seeding legs are shown in Fig. 6. The number concentration of cloud droplets is obtained from the Cloud Aerosol Spectrometer (CAS). The precipitation rate is calculated from the Cloud Imaging Probe (CIP) drop size distributions $N(D)$ as $R=\frac{\pi}{6} \int_{0}^{\infty} N(D) D^{3} u(D) \mathrm{d} D$, where $u(D)$ is the fall speed of particle size $D$ (Rogers and Yau, 1989). The effective diameter is calculated in two ways: (i) first, it is calculated from drop size distributions (DSDs) obtained from CAS to show the changes in cloud droplet size exclusively (shown as numbers in Table 3); (ii) second, it is calculated from DSDs obtained by combining the CAS and CIP probe data to include cloud droplets, drizzle and rain drop embryos (shown in Fig. 6a as well as shown as numbers in parentheses in Table 3). The first two channels (or bins) from the CIP probe overlap with the last two bins of the CAS, but the 


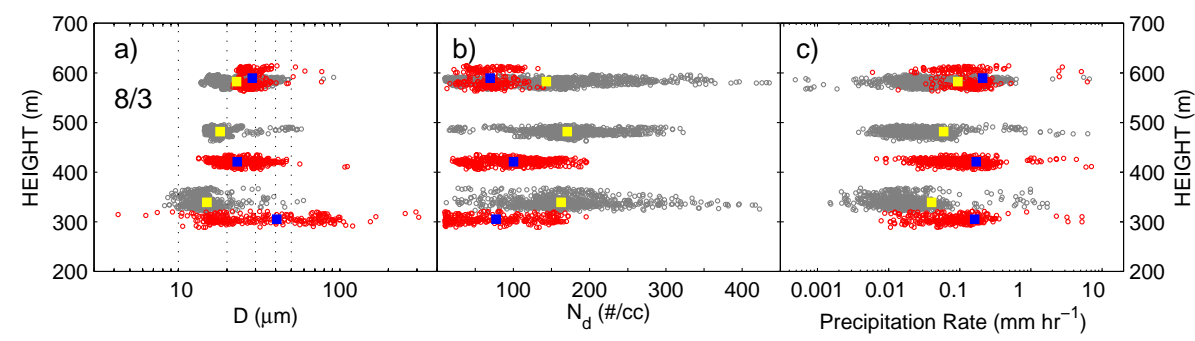

Figure 6. Changes in droplets' (a) size, (b) number concentration, and (c) drizzle rate during cloud-base, mid-cloud and cloud-top legs on 3 August 2011. Data obtained from pre-seeding legs (1 s values) are shown as grey (mean value as yellow square); data obtained from post-seeding flights are shown as red (mean value as blue square). Panels (b) and (c) are calculated from the drop size distribution (DSD) obtained from CAS and CIP probes, respectively. Panel (a) is calculated from DSDs obtained by combing the CAS and CIP probes.

Table 3. The mean value of effective diameter $D$, number concentrations $N_{d}$ of cloud droplets, precipitation rate, $R$, and the median value of calculated radar reflectivity $Z$ on 3 August 2011 for pre- and post-seeding legs at cloud-top, mid-cloud and cloud-base heights. $D$ shown in the parentheses is calculated from drop size distributions obtained by combining the CAS and CIP probes.

\begin{tabular}{|c|c|c|c|c|c|c|c|c|c|c|}
\hline $\begin{array}{l}3 \text { Aug } \\
2011\end{array}$ & \multicolumn{2}{|c|}{$D(\mu \mathrm{m})$} & \multicolumn{2}{|c|}{$N_{d}\left(\mathrm{~cm}^{-3}\right)$} & \multicolumn{2}{|c|}{$\mathrm{R}\left(\mathrm{mm} \mathrm{h}^{-1}\right)$} & \multicolumn{2}{|c|}{$\operatorname{LWC}\left(\mathrm{g} \mathrm{m}^{-3}\right)$} & \multicolumn{2}{|c|}{$Z(\mathrm{dBz})$} \\
\hline Legs & $\begin{array}{l}\text { Pre- } \\
\text { seeding }\end{array}$ & $\begin{array}{l}\text { Post- } \\
\text { seeding }\end{array}$ & $\begin{array}{l}\text { Pre- } \\
\text { seeding }\end{array}$ & $\begin{array}{l}\text { Post- } \\
\text { seeding }\end{array}$ & $\begin{array}{l}\text { Pre- } \\
\text { seeding }\end{array}$ & $\begin{array}{l}\text { Post- } \\
\text { seeding }\end{array}$ & $\begin{array}{l}\text { Pre- } \\
\text { seeding }\end{array}$ & $\begin{array}{l}\text { Post- } \\
\text { seeding }\end{array}$ & $\begin{array}{l}\text { Pre- } \\
\text { seeding }\end{array}$ & $\begin{array}{l}\text { Post- } \\
\text { seeding }\end{array}$ \\
\hline Top & $\begin{array}{l}21.4 \pm 4.9 \\
(22.9 \pm 7.1)\end{array}$ & $\begin{array}{l}26.2 \pm 3.4 \\
(29.9 \pm 8.8)\end{array}$ & $143 \pm 77$ & $70 \pm 24$ & $0.09 \pm 0.27$ & $0.21 \pm 0.57$ & $0.31 \pm 0.10$ & $0.25 \pm 0.06$ & -31.8 & -17.1 \\
\hline Mid & $\begin{array}{l}17.2 \pm 2.39 \\
(18.1 \pm 4.7)\end{array}$ & $\begin{array}{l}18.1 \pm 2.8 \\
(23.9 \pm 9.3)\end{array}$ & $171 \pm 46$ & $100 \pm 42$ & $0.06 \pm 0.28$ & $0.17 \pm 0.49$ & $0.26 \pm 0.05$ & $0.12 \pm 0.05$ & -32.1 & -16.3 \\
\hline Base & $\begin{array}{l}13.5 \pm 1.7 \\
(15.0 \pm 3.8)\end{array}$ & $\begin{array}{l}16.6 \pm 7.0 \\
(44.3 \pm 37.4)\end{array}$ & $162 \pm 56$ & $77 \pm 50$ & $0.04 \pm 0.14$ & $0.16 \pm 0.50$ & $0.09 \pm 0.04$ & $0.04 \pm 0.03$ & -31.0 & -13.8 \\
\hline
\end{tabular}

CIP has poor accuracy relative to the CAS for the overlapped ranges, therefore the first two CIP size bins were discarded when the data is combined.

Before seeding (grey in Fig. 6a), the majority of droplets had diameters between 10 and $30 \mu \mathrm{m}$. After seeding (red), the main population showed a significant broadening and an increase in sizes from a few $\mu \mathrm{m}$ to hundreds of $\mu \mathrm{m}$. The mean effective diameter of cloud droplets was between 13.5 and $21.4 \mu \mathrm{m}$ from the pre-seeding legs, and between 16.6 and $26.2 \mu \mathrm{m}$ from the post-seeding legs (Table 3 ). The mean effective diameters of droplets that include drizzle and rain drop embryos ( $D$ shown in the parentheses in Table 3 ) ranged between $\sim 15$ and $23 \mu \mathrm{m}$ for the pre-seeding legs, and between $\sim 24$ and $44 \mu \mathrm{m}$ for the post-seeding legs, suggestive of an increase in size of drizzle and rain drop embryos more than that of cloud droplets after seeding. Furthermore, a substantial decrease in cloud droplet number concentration $\left(N_{d}\right)$ was also observed during post-seeding legs (Fig. 6b, Table 3). The mean $N_{d}$ calculated from pre-seeding legs was about $140-170 \mathrm{~cm}^{-3}$ throughout the cloud, and was reduced to about $70-100 \mathrm{~cm}^{-3}$ after seeding, which is consistent with what would be expected with enhanced droplet collisioncoalescence. Precipitation rates (Fig. 6c, Table 3) were less than $0.1 \mathrm{~mm} \mathrm{~h}^{-1}\left(0.04-0.09 \mathrm{~mm} \mathrm{~h}^{-1}\right)$ before seeding and increased to about $0.2 \mathrm{~mm} \mathrm{~h}^{-1}$ after seeding. The LWCs, be- fore and after seeding, are also summarized in Table 3. After seeding, LWC decreased to about $0.04-0.25 \mathrm{~g} \mathrm{~m}^{-3}$ from $0.09-0.31 \mathrm{~g} \mathrm{~m}^{-3}$. Liquid water path (LWP) was calculated by integrating an average LWC at cloud-base, mid-cloud, and cloud-top levels during pre- and post-seeding cloud sampling, after they were linearly interpolated with height. The LWP was about $52 \mathrm{~g} \mathrm{~m}^{-2}$ before seeding, and decreased to about $43 \mathrm{~g} \mathrm{~m}^{-2}$ after seeding.

As noted above, the post-seeding legs were made about $30 \mathrm{~min}$ to $1 \mathrm{~h}$ after the cloud was seeded (Table 2), allowing sufficient time for the salt seeding effects to be distributed throughout the cloud due to large eddy transport through the depth of the boundary layer operating on characteristic time scales of about $30 \mathrm{~min}$. In the flare seeding by Ghate et al. (2007), the post-seeding sampling was made about 10 to $30 \mathrm{~min}$ after the flare burns. In that case, the effects on the droplet size distribution were clearly seen, but no drizzle was observed. The lack of observable drizzle in those experiments may have been partly due to the premature postseeding cloud sampling (i.e., 10 to 30 min after seeding), but may also have been due to the nature of the flares that they used, which produce higher concentration of smaller-sized salt particles than the salt power used in this experiment.

Changes in drop size distributions, before and after seeding, are shown in Fig. 7. Overall, number concentration 


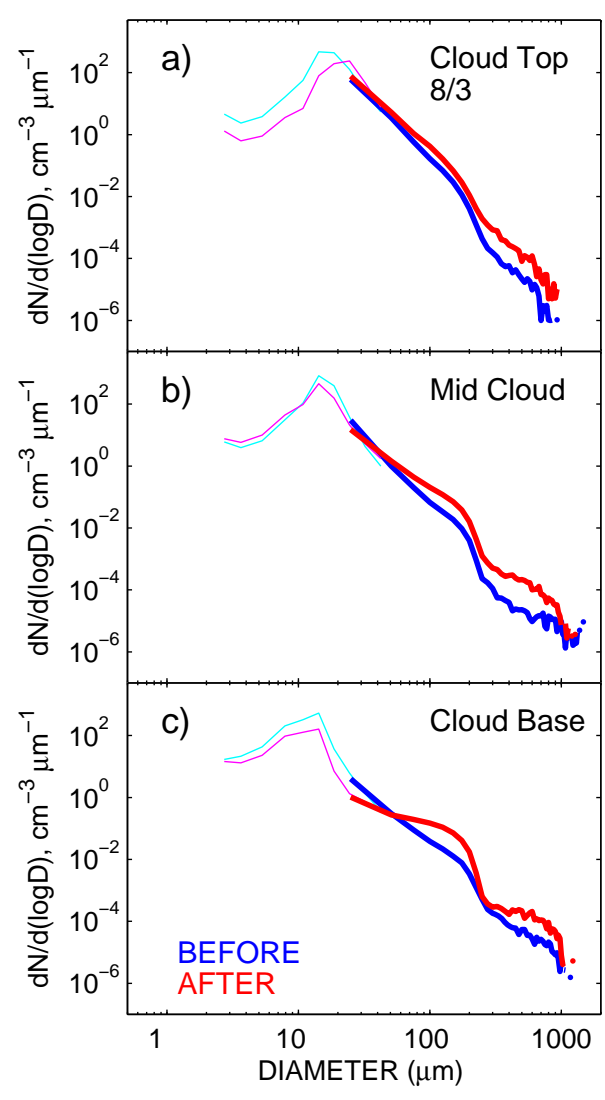

Figure 7. Drop size distributions (DSDs) obtained from level legs at (a) cloud top, (b) mid-cloud, and (c) cloud base before (blue) and after (red) seeding on 3 August 2011. DSDs are calculated from CAS (thin) and CIP (thick) probes for the pre- and post-seeding legs. "BEFORE" and "AFTER" indicate pre- and post-seeding legs, respectively. The values are based on the averages for each level leg, shown in Fig. 4 and Table 2.

of smaller sized cloud droplets (e.g., $D<20-50 \mu \mathrm{m})$ decreased during the post-seeding legs (see the changes between blue and red), whereas the number concentration of large droplets $(D>50 \mu \mathrm{m})$ increased. The decrease in smaller sized droplets concentration is large at the cloud top, where the GCCN is directly injected, and also near the cloud base. The maximum diameter, at which the depletion of smallsized droplets occurred, increased closer to the cloud base. For example, near cloud tops, droplets smaller than $20 \mu \mathrm{m}$ decreased in number substantially. At cloud base, number concentrations of droplets smaller than $50 \mu \mathrm{m}$ have decreased. The increase in larger sized droplets during the post-seeding legs was substantial through all three cloud level legs. In particular, bimodal patterns were observed at the cloud base in the ranges between 50 and $\sim 200 \mu \mathrm{m}$, and between 300 and $\sim 1000 \mu \mathrm{m}$. Increases in larger drops (e.g., $D>50 \mu \mathrm{m})$ and decreases in smaller-sized droplets (e.g., $D<20-30 \mu \mathrm{m}$ ) during post-seeding legs are consistent with the enhancement of collision-coalescence effects due to the salt. These changes in the droplet distributions in the seeded areas (i.e., enhancement of a tail of large drops on the upper end of droplet distribution) are similar to those reported by Ghate et al. (2007) in areas of Sc clouds seeded by flares, and by Rosenfeld et al. (2002) in the convective clouds seeded by GCCN, as well as by other numerical experiments on the impact of GCCN on precipitation and cloud structures (e.g., Johnson, 1982; Cooper et al., 1997; Rosenfeld et al., 2010).

To relate the injected concentrations of GCCN to drizzle drop concentrations, changes in droplet number concentrations for drops larger than 50, 100, and $200 \mu \mathrm{m}$ are calculated for the periods of pre- and post-seeding legs (Table 4). Drizzle drop number concentrations are calculated from CIP probe, and the numbers are average concentrations at three cloud levels (cloud-top, mid-cloud, cloud-base). In Table 4, the total number concentrations of GCCN larger than $D>50 \mu \mathrm{m}$ increased by an order of $10^{-1} \mathrm{~cm}^{-3}$ on average. The degree of increase in total number concentration decreased as the critical size increased, such as an increase of GCCN concentration of about $10^{-2} \mathrm{~cm}^{-3}$ for $D>100 \mu \mathrm{m}$, and about $10^{-4} \mathrm{~cm}^{-3}$ for $D>200 \mu \mathrm{m}$. These calculations showed that the increase in concentrations of larger droplets was about the same order of magnitude as our estimates of the salt concentrations dispersed from the aircraft. Furthermore, the greatest increase was found at the cloud-top height, where the salt powder was injected for all three critical sizes (not shown).

Radar returns from the upward-facing cloud radar during the cloud-base level legs, before and after seeding, are shown in Fig. 8. Cloud-base level legs were conducted with the TO flying near the cloud-base altitude at average height of 339 and $307 \mathrm{~m}$ during the pre- and post-seeding legs, respectively. Before seeding, (Fig. 8a), radar returns reached about $270 \mathrm{~m}$ above the level leg altitude (i.e., $609 \mathrm{~m}$ mean sea level (MSL); $270 \mathrm{~m}$ above radar level $+339 \mathrm{~m}$ from the ground), and the radar reflectivity was on average about $-37 \mathrm{dBz}$ with maximum of $-25 \mathrm{dBz}$ in a height range of 50 and $100 \mathrm{~m}$ above the radar, for example. During the post-seeding legs (Fig. 8b), radar echoes appeared up to about $300 \mathrm{~m}$ above the level leg altitude (i.e., $\sim 607 \mathrm{~m} \mathrm{MSL)}$ ). The average radar reflectivity between 18:49:32 and 18:49:40 in a height range of 50 and $100 \mathrm{~m}$, for example, was about $-21 \mathrm{dBz}$ with maximum of $-18 \mathrm{dBz}$. The radar measurements in Fig. 8 showed a significant increase in radar returns during the post-seeding legs compared with the pre-seeding legs, although the cloudtop height and cloud depths are nearly identical for the two cases.

The time series of radar reflectivity for the period of increased radar reflectivity (box in Fig. 8b) was shown in Fig. 8c along with LWC and drizzle rates (Fig. 8d). In Fig. 8d, LWC decreased as drizzle rates increased, indicating that drizzle may be consuming the cloud water. In Fig. $8 \mathrm{c}$ and d, the variability in the radar reflectivity was clearly correlated with the drizzle rates observed at this level and inversely correlated with the cloud liquid water content. 
Table 4. Total droplet number concentrations larger than critical sizes. Numbers are average concentrations at three cloud levels.

\begin{tabular}{llll}
\hline & $\begin{array}{l}\text { Before } \\
\left(\mathrm{cm}^{-3}\right)\end{array}$ & $\begin{array}{l}\text { After } \\
\left(\mathrm{cm}^{-3}\right)\end{array}$ & $\begin{array}{l}\text { Difference } \\
\left(\mathrm{cm}^{-3}\right)\end{array}$ \\
\hline$D>50 \mu \mathrm{m}$ & 0.4 & 0.6 & 0.2 \\
$D>100 \mu \mathrm{m}$ & $1.6 \times 10^{-2}$ & $4.7 \times 10^{-2}$ & $3.2 \times 10^{-2}$ \\
$D>200 \mu \mathrm{m}$ & $3.1 \times 10^{-4}$ & $1.2 \times 10^{-3}$ & $3.4 \times 10^{-4}$ \\
\hline
\end{tabular}
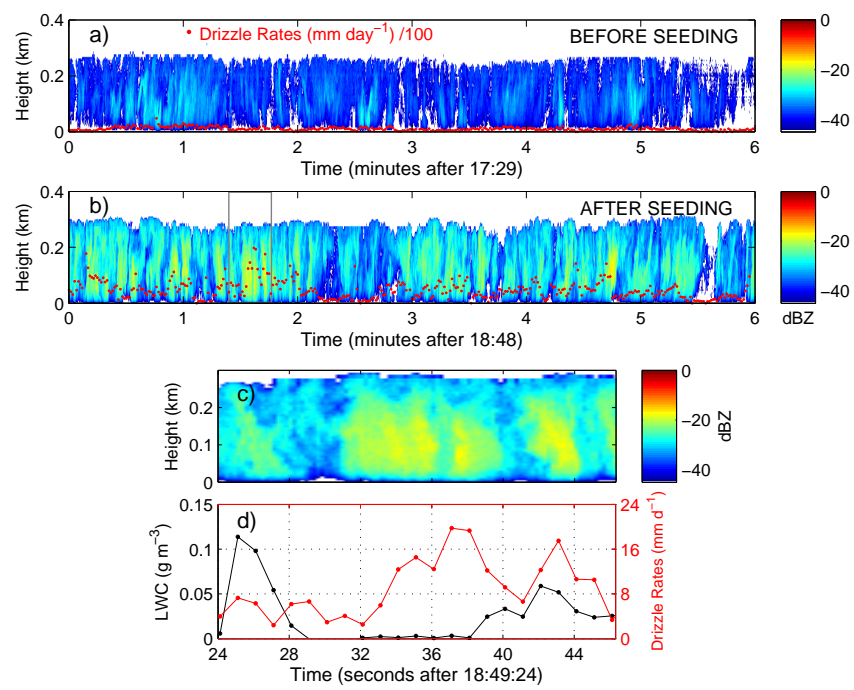

Figure 8. (a) The radar reflectivity (in $\mathrm{dBz}$, reflectivity $Z$ is proportional to $D^{6}$ of droplet diameters) shows precipitation above the cloud radar in (a) an area of cloud sampled before seeding and the (b) same air mass sampled after seeding during cloud-base level leg. $y$ axes in (a)-(c) indicate the altitudes above the radar during the cloud-base level leg. The drizzle rates in (a) and (b) are estimated from the CIP (units of hundredth of $\mathrm{mm}^{-1 a y}{ }^{-1}$ ). The outlined box in panel (b) indicates where a detailed analysis is made for (c) the radar reflectivity in $\mathrm{dBz}$ and (d) drizzle rates (from CIP) in $\mathrm{mm} \mathrm{day}^{-1}$ and the cloud liquid water content (from PVM-100) in $\mathrm{g} \mathrm{m}^{-3}$.

We further calculated the radar reflectivity at the level of cloud legs by combining data from the cloud and precipitation probes before and after seeding as comparison to the actual radar measurements. Radar reflectivity is calculated as $z=\int N(D) D^{6} \mathrm{~d} D$, where $N(D)$ is the drop size distribution (DSD) of particle size $D$, which is obtained from CAS and CIP, in units of $\mathrm{mm}^{6} \mathrm{~m}^{-3}$. Radar reflectivity $Z$ is reported in units of $\mathrm{dBz}$, where $Z=10 \log (z)$. The calculated median radar reflectivities for pre- and post-seeding legs were $-32 \mathrm{dBz}<Z<-31 \mathrm{dBz}$, and $-17 \mathrm{dBz}<Z<-14 \mathrm{dBz}$, respectively (Table 3 ), which is consistent with typical values of $Z$ for non-precipitating and precipitating clouds (Jung, 2012; Frisch et al., 1995). The large changes in the radar reflectivity between the pre- and post-seeding cloud-base legs

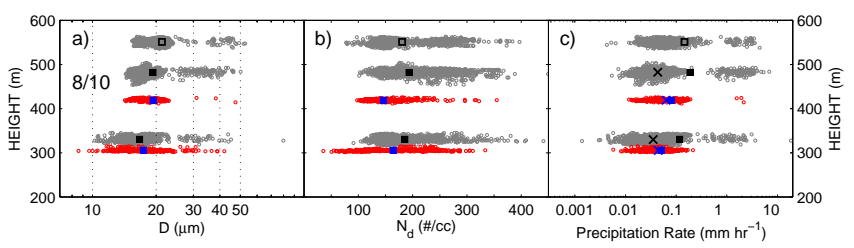

Figure 9. As in Fig. 6, but for 10 August 2011, where the cloud is initially precipitating at the time of seeding. Data obtained from pre-seeding legs are shown as grey (mean value as black square); data obtained from post-seeding legs are shown as red (mean value as blue square). Median values of drizzle rates are shown as cross symbols in (c).

(Fig. 8) were consistent with the changes in the calculated reflectivity.

Clouds were seeded on another TO flight made on $10 \mathrm{Au}-$ gust (details are not shown here). Although a similar effective seeding and sampling strategy was used on that flight (Fig. A1), no additional precipitation enhancement was noted. The cloud depth on the day was about $300-350 \mathrm{~m}$, similar to that on 3 August but with lower cloud bases (Table A1). The cloud deck was precipitating at the time of seeding (confirmed with radar reflectivity and drop size distribution, not shown), and the accumulation mode aerosol was less than $200 \mathrm{~cm}^{-3}$ in the boundary layer with little variation (not shown).

Changes in droplet size $(D)$, number concentrations $\left(N_{d}\right)$, and precipitation rate $(R)$ between the pre- and post-seeding legs are shown in Fig. 9 for the 10 August case. Before seeding, cloud droplet number concentrations were about 180 $190 \mathrm{~cm}^{-3}$ from cloud base to cloud top; they then decreased to $150-160 \mathrm{~cm}^{-3}$ after seeding (Fig. 9b). However, the decrease is not as large as that observed on 3 August. The mean precipitation rate (Fig. 9c) decreased after seeding, from 0.15 to $0.1 \mathrm{~mm} \mathrm{~h}^{-1}$, though the median precipitation rate was almost the same and/or slightly enhanced from 0.04 to 0.05 $0.06 \mathrm{~mm} \mathrm{~h}^{-1}$. These results are consistent with the previous modeling results, which demonstrate that the injection of GCCN has the greatest potential for altering cloud behavior in non-precipitating clouds having a high concentration of small drops and/or aerosol (e.g., Feingold et al., 1999; Yin et al., 2000a; Lu and Seinfeld, 2005; Zhang et al., 2006; Jensen and Lee, 2008), and hence, conditions on 10 August 2011 were not optimal for generating a strong precipitation signal, as confirmed by our measurements.

\section{Summary and conclusions}

To study the effect of giant cloud condensation nuclei (GCCN) on precipitation in Sc clouds, we released 1-10 $\mu \mathrm{m}$ diameter salt particles from an aircraft while flying near cloud tops during the Eastern Pacific Emitted Aerosol Cloud Experiment (E-PEACE, 2011). Results from the 3 August 
2011 flight provide evidence for a strong change in droplet number and size in the clouds that were seeded with giant nuclei. The GCCN were released in a cross-wind zigzag pattern at a fixed level (near cloud top) in a uniform cloud deck using a device designed to minimize the clumping of the salt and provide concentrations in the range of $10^{-2}$ to $10^{-4} \mathrm{~cm}^{-3}$. The seeded area was then sampled downstream as estimated by advection of the area using observed winds and the elapsed time between seeding and post-seeding cloud sampling periods. During the post-seeding cloud sampling legs, conducted 30-60 min after seeding, the mean cloud droplet size had increased, droplet number concentrations decreased and large drops enhanced in the size distributions. Average drizzle rates increased from about 0.05 to $0.20 \mathrm{~mm} \mathrm{~h}^{-1}$. Strong radar returns associated with drizzle were observed on the post-seeding cloud-base legs and were accompanied by a substantial depletion of the cloud liquid water content. The changes were large enough to suggest that the salt seeding resulted in a four-fold increase in the cloud-base rainfall rate and an associated depletion of the cloud water due to rainout. The reduction of cloud droplet number concentrations indicates invigorated collision-coalescence between drops. Furthermore, the drop diameter at all altitudes in the cloud deck increased in the seeded area. Thus, the observational evidence confirms the particular chain of events that is expected after a cloud seeding event: faster onset of rain owing to the broadening of cloud drop distribution.
The results show the enhancement of precipitation by artificially introducing GCCN into a stratocumulus cloud. As in Ghate et al. (2007), the usefulness of marine Sc clouds to study cause-and-effect relationships associated with GCCN is demonstrated. However, tracking the exact movement of the cloudy air mass that has been seeded with GCCN using a single aircraft is challenging. Use of tracers such as radar chaff (Jung and Albrecht, 2014) or $\mathrm{SF}_{6}$ (Rosenfeld et al., 2002, 2010) for tracking the seeded areas would facilitate these studies of cloud modification by GCCN. Furthermore, a scanning-cloud radar would provide a full view of the 3D temporal evolution of the cloud in which GCCN are injected. Nevertheless, the results in this study support the idea that giant nuclei - produced either naturally or anthropogenically - can initiate drizzle and impact the cloud structure as shown in Levin et al. (2005) for dust aerosols coated with sea salt and sulfate during the Mediterranean Israeli Dust Experiment campaign. Since the concentrations of GCCN used in this study are in the range of those observed in nature under strong wind conditions, we concur with the conclusions of Jensen and Lee (2008) that it may be necessary to include GCCN effects in climate models. 


\section{Appendix A: Summary and flight patterns of salt seeding experiments}

During E-PEACE, salt powder was ejected into cloud decks during nine flights. To better understand the individual seeding cases, the summary of salt seeding experiments is given in Table A1.

According to Table A1, there were four less-than-ideal and two ideal cases of seeding experiments in terms of seeding and sampling strategy. Flight patterns of those six seeding experiments are shown in Fig. A1.

Figure A1 showed that the parallel post-seeding sampling with zigzag seeding pattern (c and d; 3 August and $10 \mathrm{Au}-$ gust 2011) was found to be the most effective flight pattern to capture the seeding effects. In contrast, the perpendicular patterns between the seeding and post-seeding patterns reduced the chance of proper sampling of a salted/seeded air mass during the post-seeding flights. In this case, there was no sufficient time for the seeded air mass to be sampled during the post-seeding sampling legs.
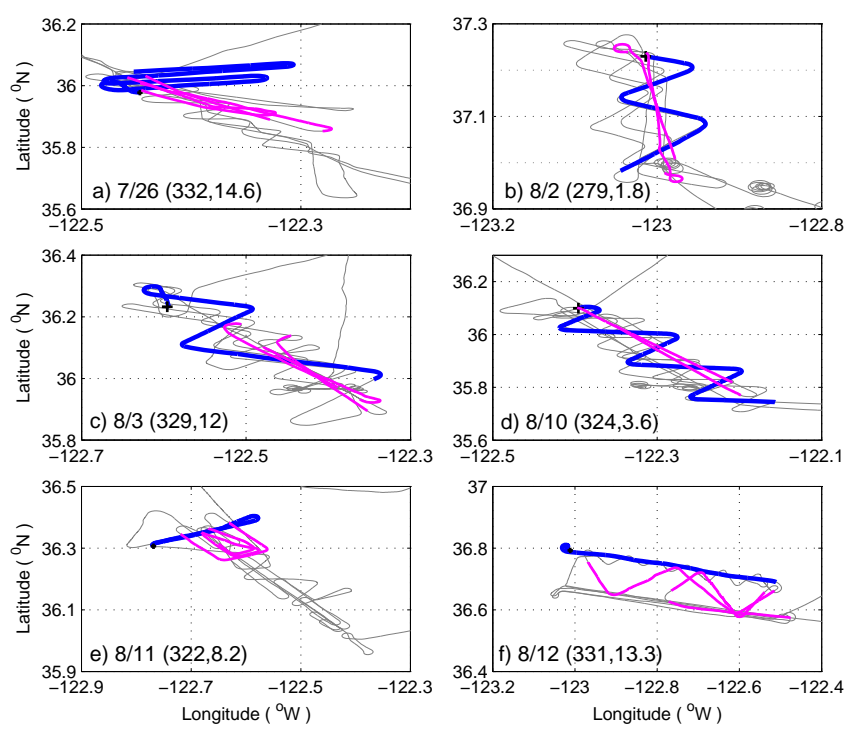

Figure A1. Flight patterns during salt seeding (blue) and postseeding cloud sampling legs (magenta) for some of the seeding flights. First and second numbers inside the parentheses indicate the mean wind direction (degree) and mean wind speed $\left(\mathrm{m} \mathrm{s}^{-1}\right)$ during the salt-seeding leg, respectively. 
Table A1. Summary of salt seeding experiments.

\begin{tabular}{|c|c|c|}
\hline Date & Description & $\begin{array}{l}\text { Cloud level (m) from Table } 4 \text { of } \\
\text { Russell et al. (2013) }\end{array}$ \\
\hline 8 July & The TO did not sample the cloud after salt seeding. No post-seeding legs. & $\begin{array}{l}257-362 \mathrm{~m} \\
\text { (Thin cloud layer) }\end{array}$ \\
\hline 9 July & $\begin{array}{l}\text { We performed two salt seeding experiments. However, there was no post-seeding } \\
\text { cloud-sampling leg for the first experiment. For the second experiment, the refer- } \\
\text { ence cloud legs (i.e., non-salted cloud sampling legs) were possibly contaminated } \\
\text { by the first salt seeding experiment by the method shown in Fig. } 5\end{array}$ & $\begin{array}{l}283-570 \mathrm{~m} \\
\text { (Thick, wet cloud layer) }\end{array}$ \\
\hline 26 July & $\begin{array}{l}\text { The seeding/sampling strategy was not an ideal (seeding and sampling pattern was } \\
\text { perpendicular, and there was no sufficient post-seeding sampling). During the post- } \\
\text { seeding legs at the mid-cloud and cloud-base heights, the seeded area was already } \\
\text { advected far southeast. Only cloud-top legs (post-seeding flight) were sampled from } \\
\text { the estimated seeding area, and the seeding effects were shown at least in the cloud- } \\
\text { top leg. }\end{array}$ & $\begin{array}{l}253-560 \mathrm{~m} \\
\text { (Thick cloud layer) }\end{array}$ \\
\hline 29 July & $\begin{array}{l}\text { NO post-seeding sampling legs. Right after injecting salt power, TO sampled the } \\
\text { cloud at the same height as seeding, but it was found that the TO flew slightly above } \\
\text { the seeding height (no LWC is detected). }\end{array}$ & $\begin{array}{l}265-534 \mathrm{~m} \\
\text { (High, wet clouds) }\end{array}$ \\
\hline 2 August & $\begin{array}{l}\text { The seeding/sampling strategy was not an ideal. Intersection with seeded area was } \\
\text { small since the post-seeding was not made in the downstream of the seeding area. } \\
\text { Seeding effect was not seen. }\end{array}$ & $\begin{array}{l}310-613 \mathrm{~m} \\
\text { (Thick, wet cloud layer) }\end{array}$ \\
\hline 3 August & Descent case solely based on the strategy (shown in the manuscript) & $\begin{array}{l}309-628 \mathrm{~m} \\
(\text { Thick cloud), } \\
* \mathrm{H} \sim 369 \mathrm{~m}\end{array}$ \\
\hline 10 August & $\begin{array}{l}\text { Descent case solely based on the strategy. However, the cloud was already precipi- } \\
\text { tating when it was seeded. }\end{array}$ & $\begin{array}{l}286-553 \mathrm{~m} \\
\text { (Low clouds), } \\
* \mathrm{H} \sim 367 \mathrm{~m}\end{array}$ \\
\hline 11 August & $\begin{array}{l}\text { The seeding/sampling strategy was not an ideal. During the mid-cloud and cloud- } \\
\text { top legs (post-seeding flight), the seeded area was already advected far southeast. } \\
\text { Only cloud-base legs were (barely) located within the seeded area. }\end{array}$ & $\begin{array}{l}440-600 \mathrm{~m} \\
\text { (Two broken cloud layers) }\end{array}$ \\
\hline 12 August & $\begin{array}{l}\text { The seeding/sampling strategy was not an ideal. Post-seeding cloud sampling leg } \\
\text { on the cloud base only (barely) sampled the seeded area (no sufficient data for the } \\
\text { post-seeding legs). }\end{array}$ & $\begin{array}{l}278-578 \mathrm{~m} \\
\text { (Thick cloud layer) }\end{array}$ \\
\hline
\end{tabular}

* $\mathrm{H}$ (cloud thickness) is calculated from the vertical profile of LWC obtained from soundings on the day. 
Acknowledgements. The E-PEACE field campaign and modeling studies were funded by the National Science Foundation (AGS-1013423; AGS-1008848; AGS-1013381; AGS-1013319; ATM-0744636; AGS-0821599; ATM-0349015) and the Office of Naval Research (N00014-11-1-0783; N00014-10-1-0811; N00014-10-1-0200; N00014-08-1-0465). The authors gratefully acknowledge the crew of the CIRPAS Twin Otter for their assistance during the field campaign and Daniel Rosenfeld for providing the powdered salt. We also appreciate the outstanding efforts of Tom Snowdon on the design and fabrication of the salt-powder dispensing system. We greatly appreciate the thoughtful comments provided by the reviewer Jorgen Jensen.

Edited by: L. Zhang

\section{References}

Cooper, W. A., Bruintjes, R. T., and Mather, G. K.: Calculations pertaining to hygroscopic seeding with flares, J. Appl. Meteorol., 36, 1449-1469, doi:10.1175/15200450(1997)036<1449:CPTHSW>2.0.CO;2, 1997.

Feingold, G., Cotton, W. R., Kreidenweis, S. M., and Davis, J. T.: The impact of giant cloud condensation nuclei on drizzle formation in stratocumulus: Implications for cloud radiative properties, J. Atmos. Sci., 56, 4100-4117, 1999.

Frisch, A. S., Fairall, C. W., and Snider, J. B.: Measurement of stratus cloud and drizzle parameters in ASTEX with a $\mathrm{K} \alpha$-Band Doppler Radar and a microwave radiometer, J. Atmos. Sci., 52, 2788-2799, doi:10.1175/15200469(1995)052<2788:MOSCAD>2.0.CO;2, 1995.

Ghate, V. P., Albrecht, B. A., Kollias, P., Jonsson, H. H., and Breed, D. W.: Cloud seeding as a technique for studying aerosol-cloud interactions in marine stratocumulus, Geophys. Res. Lett., 34, L14807, doi:10.1029/2007GL029748, 2007.

Hartmann, D. L., Ockert-Bell, M. E., and Michelsen, M. L.: The effect of cloud type on earth's energy balance - Global analysis, J. Climate, 5, 1281-1304, 1992.

Jensen, J. B. and Lee, S.: Giant sea-salt aerosols and warm rain formation in marine stratocumulus, J. Atmos. Sci., 65, 3678-3694, doi:10.1175/2008JAS2617.1, 2008.

Johnson, D.: The role of giant and ultragiant aerosol particles in warm rain initiation, J. Atmos. Sci., 39, 448-460, 1982.

Jung, E.: Aerosol-cloud-precipitation interactions in the trade wind boundary layer, available at: http://gradworks.umi.com/35/49/ 3549376.html (last access: 6 November 2014), 2012.

Jung, E. and Albrecht, B.: Use of radar chaff for studying circulations in and around shallow cumulus clouds, J. Appl. Meteorol. Climatol., 53, 2058-2071, doi:10.1175/JAMC-D-13-0255.1, 2014.

L'Ecuyer, T. S., Berg, W., Haynes, J., Lebsock, M. and Takemura, T.: Global observations of aerosol impacts on precipitation occurrence in warm maritime clouds, J. Geophys. Res. Atmos., 114, D09211, doi:10.1029/2008JD011273, 2009.
Levin, Z., Teller, A., Ganor, E., and Yin, Y.: On the interactions of mineral dust, sea-salt particles, and clouds: A measurement and modeling study from the Mediterranean Israeli Dust Experiment campaign, J. Geophys. Res., 110, D20202, doi:10.1029/2005JD005810, 2005.

Lu, M. L. and Seinfeld, J. H.: Study of the aerosol indirect effect by large-eddy simulation of marine stratocumulus, J. Atmos. Sci., 62, 3909-3932, doi:10.1175/jas3584.1, 2005.

Mather, G. K., Terblanche, D. E., Steffens, F. E., and Fletcher, L.: Results of the South African cloud-seeding experiments using hygroscopic flares, J. Appl. Meteor., 36, 1433-1447, 1997.

Rogers, R. R. and Yau, M. K.: A short course in cloud physics, Third Edition. International Series in Natural Philosophy, Pergamon Press, Oxford, 290 pp., 1989.

Rosenfeld, D., Lahav, R., Khain, A., and Pinsky, M.: The role of sea spray in cleansing air pollution over ocean via cloud processes, Science, 297, 1667-1670, doi:10.1126/science.1073869, 2002.

Rosenfeld, D., Axisa, D., Woodley, W. L., and Lahav, R.: A quest for effective hygroscopic cloud seeding, J. Appl. Meteorol. Climatol., 49, 1548-1562, doi:10.1175/2010JAMC2307.1, 2010.

Russell, L. M., Sorooshian, A., Seinfeld, J. H., Albrecht, B. A., Nenes, A., Ahlm, L., Chen, Y. C., Coggon, M., Craven, J. S., Flagan, R. C., Frossard, A. A., Jonsson, H., Jung, E., Lin, J. J., Metcalf, A. R., Modini, R., Mülmenstädt, J., Roberts, G. C., Shingler, T., Song, S., Wang, Z., and Wonaschütz, A.: Eastern pacific emitted aerosol cloud experiment, B. Am. Meteorol. Soc., 94, 709-729, doi:10.1175/BAMS-D-12-00015.1, 2013.

Segal, Y., Khain, A., Pinsky, M., and Rosenfeld, D.: Effects of hygroscopic seeding on raindrop formation as seen from simulations using a 2000-bin spectral cloud parcel model, Atmos. Res., 71, 3-34, doi:10.1016/j.atmosres.2004.03.003, 2004.

Segal, Y., Pinsky, M., and Khain, A.: The role of competition effect in the raindrop formation, Atmos. Res., 83, 106-118, doi:10.1016/j.atmosres.2006.03.007, 2007.

Slingo, A.: Sensitivity of the Earth's radiation budget to changes in low clouds, Nature, 343, 49-51, doi:10.1038/343049a0, 1990.

Sorooshian, A., Wang, Z., Feingold, G., and L'Ecuyer, T. S.: A satellite perspective on cloud water to rain water conversion rates and relationships with environmental conditions, J. Geophys. Res.Atmos., 118, 6643-6650, doi:10.1002/jgrd.50523, 2013.

Takahashi, T.: Warm rain, giant nuclei and chemical balance-A numerical model, J. Atmos. Sci., 33, 269-286, 1976.

Tzivion, S., Reisin, T., and Levin, Z.: Numerical simulation of hygroscopic seeding in a convective cloud, J. Appl. Meteorol., 33, 252-266,1994.

World Meteorological Organization: Report of the WMO workshop on hygroscopic seeding. WMP Rep. 35, WMO/TD 1006, Geneva, Switzerland, 68 pp., 2000.

Yin, Y., Levin, Z., Reisin, T. G., and Tzivion, S.: The effects of giant cloud condensation nuclei on the development of precipitation in convective clouds - a numerical study, Atmos. Res., 53, 91-116, doi:10.1016/S0169-8095(99)00046-0, 2000a.

Yin, Y., Levin, Z., Reisin, T. G., and Tzivion, S.: Seeding convective clouds with hygroscopic flares: Numerical simulations using a cloud model with detailed microphysics, J. Appl. Meteorol., 39, 1460-1472, 2000b. 
Zhang, L., Michelangeli, D. V., and Taylor, P. A.: Influence of aerosol concentration on precipitation formation in lowlevel, warm stratiform clouds, J. Aerosol Sci., 37, 203-217, doi:10.1016/j.jaerosci.2005.04.002, 2006.
Zheng, X., Albrecht, B., Jonsson, H. H., Khelif, D., Feingold, G., Minnis, P., Ayers, K., Chuang, P., Donaher, S., Rossiter, D., Ghate, V., Ruiz-Plancarte, J., and Sun-Mack, S.: Observations of the boundary layer, cloud, and aerosol variability in the southeast Pacific near-coastal marine stratocumulus during VOCALSREx, Atmos. Chem. Phys., 11, 9943-9959, doi:10.5194/acp-119943-2011, 2011. 